\title{
Optimal Design of Water Distribution Systems Based on Entropy and Topology
}

\author{
Salah H. A. Saleh • Tiku T. Tanyimboh
}

Received: 22 December 2013 / Accepted: 22 May 2014 /

Published online: 8 June 2014

(C) The Author(s) 2014. This article is published with open access at Springerlink.com

\begin{abstract}
A new multi-objective evolutionary optimization approach for joint topology and pipe size design of water distribution systems is presented. The algorithm proposed considers simultaneously the adequacy of flow and pressure at the demand nodes; the initial construction cost; the network topology; and a measure of hydraulic capacity reliability. The optimization procedure is based on a general measure of hydraulic performance that combines statistical entropy, network connectivity and hydraulic feasibility. The topological properties of the solutions are accounted for and arbitrary assumptions regarding the quality of infeasible solutions are not applied. In other words, both feasible and infeasible solutions participate in the evolutionary processes; solutions survive and reproduce or perish strictly according to their Pareto-optimality. Removing artificial barriers in this way frees the algorithm to evolve optimal solutions quickly. Furthermore, any redundant binary codes that result from crossover or mutation are eliminated gradually in a seamless and generic way that avoids the arbitrary loss of potentially useful genetic material and preserves the quality of the information that is transmitted from one generation to the next. The approach proposed is entirely generic: we have not introduced any additional parameters that require calibration on a case-by-case basis. Detailed and extensive results for two test problems are included that suggest the approach is highly effective. In general, the frontier-optimal solutions achieved include topologies that are fully branched, partially- and fully-looped and, for networks with multiple sources, completely separate sub-networks.
\end{abstract}

Keywords Statistical entropy $\cdot$ Reliability-based design $\cdot$ Evolutionary optimization $\cdot$ Redundant binary codes

\section{Introduction}

The planning for a water distribution system may include topology design and sizing of components to evaluate the hydraulic properties of the system. Since failures may occur due to

S. H. A. Saleh • T. T. Tanyimboh $(\triangle)$

Department of Civil and Environmental Engineering, University of Strathclyde Glasgow, 107 Rottenrow, Glasgow G4 0NG, UK

e-mail: Tiku.tanyimboh@strath.ac.uk

S. H. A. Saleh

e-mail: salah.saleh@strath.ac.uk 
pipe material deterioration with time or sudden increase in pressure, for example, the system's reliability is worth considering also. With regard to the topology, branched systems are suitable for small and low-density rural areas, while fully or partially looped systems are proper for urban areas (Swamee and Sharma 2008). Branched systems have the disadvantage that a break in any pipe puts all consumers downstream out of service. In fully looped systems, each demand node can be supplied from the source(s) through at least two independent paths. Two supply paths are said to be independent if they do not have a pipe in common. In the literature, the joint effects of topology and pipe size optimization were dealt with typically as two separate stages in which topology design followed by pipe sizing was carried out (Rowel and Barnes 1982; Morgan and Goulter 1982, Kessler et al. 1990, Cembrowicz 1992). However, such methods neglect the strong coupling between topology and components design to varying degrees.

Also, the relationship between topology, pipe sizes and hydraulic reliability is strong. However, previous studies that included reliability generally did not optimize the topology. Various reliability measures that are easy to calculate have been suggested including statistical entropy (Tanyimboh and Templeman 1993), resilience index (Todini 2000), network resilience (Prasad and Park 2004), modified resilience index (Jayaram and Srinivasan 2008) and surplus power factor (Vaabel et al. 2006). Among these measures, statistical entropy has been shown to be the most consistent (Reca et al. 2008; Raad et al. 2010; Baños et al. 2011; Tanyimboh et al. 2011; Saleh et al. 2012). For water distribution systems, the statistical entropy may be considered a measure of the uniformity of the pipe flow rates (Tanyimboh and Templeman 1993).

Awumah et al. (1989) developed a two-stage model for optimizing the pipe sizes and topology. In the first stage, a topology model determines whether a link is to be included using integer programming. In the second stage, pipe diameters are adjusted. Awumah and Goulter (1992) also proposed an alternative approach using statistical entropy theory. Tanyimboh and Sheahan (2002) also used statistical entropy in an approach in which the topology, pipe sizing, reliability and redundancy were considered in successive stages.

Evolutionary optimization algorithms have been used also (Davidson and Goulter 1995; Walters and Smith 1995; Geem et al. 2000; Afshar and Jabbari 2007). Evolutionary algorithms often generate infeasible solutions when solving problems that involve constraints. Casespecific constraint-violation penalties (Kougias and Theodossiou 2013) that require calibration are frequently introduced to address this issue. Saleh and Tanyimboh (2013) introduced an approach that optimizes both the topology and pipe sizes. The algorithm provides a single optimal solution and reliability aspects beyond the topology were not addressed.

This paper describes a new multi-objective evolutionary approach for the simultaneous topology, pipe size and entropy-based optimization of water distribution systems. Unlike previous entropy-based approaches such as Tanyimboh and Sheahan (2002), the pipe flow directions and candidate topologies are not specified in advance. Also, the algorithm promotes full exploitation of all feasible and infeasible solutions generated to guide the search. Our algorithm includes a robust measure for the infeasibility of any solution and a seamless generic procedure for redundant binary codes. Results for two test problems in the literature are included.

\section{Optimization Approach}

The difficulties associated with constraint-violation penalties that are commonly used in evolutionary algorithms include time-consuming trial runs and parameter calibration (Dridi 
et al. 2008). On the other hand, penalty-free methods eliminate the need to design penalty functions and are relatively straightforward to implement without sacrificing the computational efficiency (Siew and Tanyimboh 2012). Also, penalty-free methods can maintain infeasible solutions that may have useful properties that may not be common in feasible solutions in successive generations of the optimization. Other constraint handling methods have been proposed (Deb et al. 2002). For example, Ray et al. (2001) suggested three stages of nondomination ranking using different combinations of the objective and constraint functions. Constraint handling in Deb et al. (2002) involves a binary tournament in which feasible solutions automatically dominate infeasible solutions. We developed a penalty-free strategy that exploits all efficient solutions generated, without introducing additional measures aimed at reducing the propagation of infeasible solutions.

\subsection{Details of the Optimization Model}

We used the EPANET 2 hydraulic simulation model (Rossman 2000) to determine the hydraulic properties of all solutions generated in the optimization process and to ensure the solutions satisfy conservation of mass and energy. The optimization model minimizes the initial construction cost, $f_{1}$, the infeasibility measure, $f_{2}$, and the number of pipes, $f_{3}$, as explained below.

$$
\begin{gathered}
f_{1}=\sum_{i j} f\left(L_{i j}, D_{i j}\right) \\
f_{2}=l+h+\left(S^{*}-S\right)+\left(S_{g}^{*}-S^{*}\right): l=\sum_{i=1}^{N} \max \left(0, R_{i}^{r e q}-R_{i}\right), \quad h=\sum_{i} \max \left(0, H_{i}^{r e q}-H_{i}\right) \\
f_{3}=\sum_{i j} p_{i j}
\end{gathered}
$$

in which $N=$ number of nodes; for pipe $i j, L_{i j}=$ length; $D_{i j}=$ diameter; $p_{i j}=1$ if pipe $i j$ is included in the topology and $p_{i j}=0$ otherwise; $H_{i}$ and $H_{i}^{r e q}=$ available and required residual head at demand node $i$, respectively; $R_{i}$ and $R_{i}^{r e q}=$ actual and required number of independent supply paths to node $i$, respectively; $S=$ entropy; $S^{*}=$ maximum entropy; and $S_{g}^{*}=$ global maximum entropy.

The function $l$ in Eq. 2 represents the total topological infeasibility of a candidate solution. The topological infeasibility at node $i$ was taken as the shortfall in the number of independent supply paths $R_{i}$. The required number of independent supply paths, $R_{i}^{r e q}$, is typically 1 and 2 , respectively, for branched and fully looped configurations. The function $h$ in Eq. 2 represents the residual head infeasibility. If $H_{i} \geq H_{i}^{r e q}$ for all demand nodes, then the solution is hydraulically feasible. The required residual head $H_{i}^{\text {req }}$ is the head at a node above which demands are satisfied in full. $H_{i}^{\text {req }}$ is typically not less than a minimum of about $7 \mathrm{~m}$ (OFWAT 2008).

For any feasible topology that has loops, there are multiple feasible sets of flow directions each of which has a maximum entropy value. $S^{*}$ is the theoretical maximum value of entropy for a particular feasible set of flow directions while $S_{g}^{*}$ is the global maximum entropy value considering all permissible topologies. The global maximum entropy value $S_{g}^{*}$ is not known a priori; our algorithm evolves the global maximum entropy solution by assuming it corresponds to the largest entropy value it has so far identified. The infeasibility measure $f_{2}$ seeks feasible 
solutions that have high values of entropy (a proxy for hydraulic reliability and redundancy). Minimizing the infeasibility measure $f_{2}$ promotes the inclusion of a range of maximum entropy solutions for which, by definition, $S=S^{*}$, in the nondominated set in addition to $S_{g}^{*}$.

To complete the characterization of the infeasibility function $f_{2}$, the entropy functions are described here briefly (Tanyimboh and Templeman 1993).

$$
S=S_{0}+\sum_{i=1}^{N} P_{i} S_{i}
$$

$S=$ entropy; $S_{0}=$ entropy of source supplies; $S_{i}=$ entropy of node $i ; P_{i}=T_{i} / T=$ fraction of the total flow through the network that reaches node $i$; $T_{i}=$ total flow that reaches node $i$; $T=$ total demand;

$$
S_{0}=-\sum_{i \in I} \frac{Q_{0 i}}{T} \ln \left(\frac{Q_{0 i}}{T}\right) ;
$$

$Q_{0 i}=$ inflow rate at source node $i$; $I=$ the set of source supply nodes;

$$
S_{i}=-\frac{Q_{i 0}}{T_{i}} \ln \left(\frac{Q_{i 0}}{T_{i}}\right)-\sum_{i j \in \text { out }\left(N_{i}\right)} \frac{Q_{i j}}{T_{i}} \ln \left(\frac{Q_{i j}}{T_{i}}\right), \quad i=1, \ldots ., N
$$

$Q_{i 0}=$ demand at node $i ; Q_{i j}=$ flow rate in pipe $i j$; and $\operatorname{out}\left(N_{i}\right)=$ set of all pipe flows from node $i$.

For a typical node with, say, two incident pipes downstream, it can be shown that $S_{i} \leq \ln (3) \approx$ 1.1 (Shannon 1948). Given that $P_{i}=T_{i} / T \leq 1.0$, it is expected that the value of the network entropy $S$ in Eq. 4 will be relatively small for the typical water distribution system. Therefore, it is expected that the contributions of the entropy terms $\left(S^{*}-S\right)$ and $\left(S_{g}^{*}-S^{*}\right)$ to the infeasibility measure $f_{2}$ in Eq. 2 will be relatively small. The objective function $f_{2}$ may be considered an entropy-augmented infeasibility measure. Minimizing $f_{2}$ aims simultaneously to satisfy residual head and topology requirements and maximize entropy. Eqs. 4-6 are an extension of the statistical entropy function that is a measure of uncertainty (Shannon 1948). In a probabilistic system the uncertainty is a maximum if all possible system states or outcomes are equally likely. Conversely, the uncertainty decreases as the probabilities associated with the states or outcomes become more unequal. The term $\left[\left(S^{*}-S\right)+\left(S_{g}^{*}-S^{*}\right)\right]=\left(S_{g}^{*}-S\right)$ in the infeasibility measure $f_{2}$ may be considered an estimate of the unrealized entropy potential; by definition its value is zero for $S=S^{*}=S_{g}^{*}$.

\subsection{Practical Topology Confirmation and Redundant Binary Codes}

We developed a topology confirmation algorithm coded in $\mathrm{C}$, to enable a consistent and biasfree fitness assessment of all feasible and infeasible solutions. The total number of paths $N P_{i}$ supplying demand node $i$ from all sources collectively was determined with regard to the pipe flow directions obtained from EPANET 2. We used an efficient path enumeration algorithm proposed by Yassin-Kassab et al. (1999). If $N P_{i}=0$, the node cannot be supplied. If $N P_{i}=1$, the node can be supplied. If $N P_{i} \geq 2$, for all nodes, a path inter-dependency investigation is carried out to check whether the network is fully looped. We adopted a practical procedure that does not involve an exhaustive enumeration of all the paths supplying each node. For a pair of independent supply paths, removing a pipe from one path does not affect the other path. Therefore, the procedure entails removing all pipes one at a time and in each case observing whether all nodes can be reached. If all nodes can be supplied from one or more sources after the removal of all pipes one by one with replacement, then all nodes have at least two independent supply paths. It is worth observing that EPANET 2 sets default values of node 
pressures and pipe flows within parts of a network that are not connected to a source. We addressed this by assigning zero flows and pressures, respectively, to such pipes and nodes.

In order to represent the vector of decision variables in a genetic algorithm, an $n$-bit binary string gives rise to $2^{n}$ different $n$-bit codes and, depending on the number of decision variables, some codes may be redundant. We assumed redundant codes represent closed pipes whose flow-carrying capacity is zero. The closed pipes are allocated pipe sizes taken from just above the upper end of the real set of available pipe diameters. The data required to implement the procedure are the unit costs for the fictitious or assumed diameters. As the fictitious diameters have no functional value, it is anticipated they will become extinct through evolution and natural selection. The benefits of this novel approach are that it is entirely generic and very practical; additional parameters that require special calibration are not introduced and preoptimization trial runs are not required. The premature loss of potentially useful genes is thus avoided, and the genetic code that is transmitted in successive generations is not degraded (Herrera et al. 1998).

\section{Computational Solution}

We used the Nondominated Sorting Genetic Algorithm (NSGA) II that has been used extensively, and its merits have been reported elsewhere (Deb et al. 2002; Dridi et al. 2008). Selection for crossover was carried out with a binary tournament. Single-point crossover was used to produce two offspring from two parents. Once the offspring population was created, the mutation operator reversed the selected bits. The optimization problem was posed as:

$$
\text { Minimize } \mathbf{f}=\left(f_{1}, f_{2}, f_{3}\right)^{\mathrm{T}}
$$

The decision variables are the pipe diameters $D_{i j}$ and link selection variables $p_{i j}$ for the entire network. To make all three objectives in Eq. 7 roughly similar in magnitude, each $f_{i}^{m}$, i.e. the value of objective $m$ for solution $i$, was normalized as

$$
f n_{i}^{m}=\left(f_{i}^{m}-f_{\min }^{m}\right) /\left(f_{\max }^{m}-f_{\min }^{m}\right) ; \forall i, \forall m
$$

In the generation in question, $f_{\min }^{m}$ and $f_{\max }^{m}=$ minimum and maximum value of objective $m$, respectively; and $f n_{i}^{m}=$ normalized value of objective $m$ for solution $i$.

In each generation of the optimization algorithm, each solution in the population is analysed using EPANET 2. The resulting pipe flow rates are used to calculate the entropy (Eq. 4). In general, numerical nonlinear optimization is required to calculate the maximum value of the entropy $S^{*}$. However, computationally efficient path entropy methods that do not involve numerical optimization directly are available. We used the "simplified path entropy method" developed by Ang and Jowitt (2005) for the single-source network example (Section 4.1) and an algorithm known as the " $\alpha$-method" developed by Yassin-Kassab et al. (1999) for the multiple-source network example (Section 4.2). Application of the $\alpha$-method involves solving a non-linear system of equations and, for a two-source network, it reduces to the solution of a single nonlinear equation for which we used the bisection method (Press et al. 2003).

\section{Results and Discussion}

Two networks from the literature were considered. The Hazen-Williams roughness coefficient for all pipes is 130 . For each network, the optimization algorithm was executed 30 times on a 


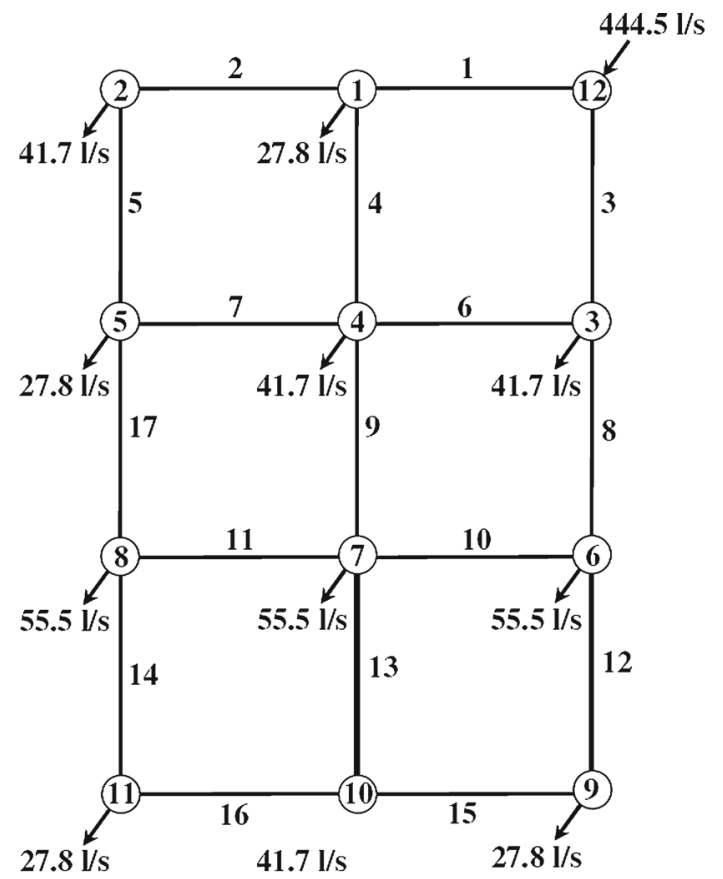

(a)Network 1

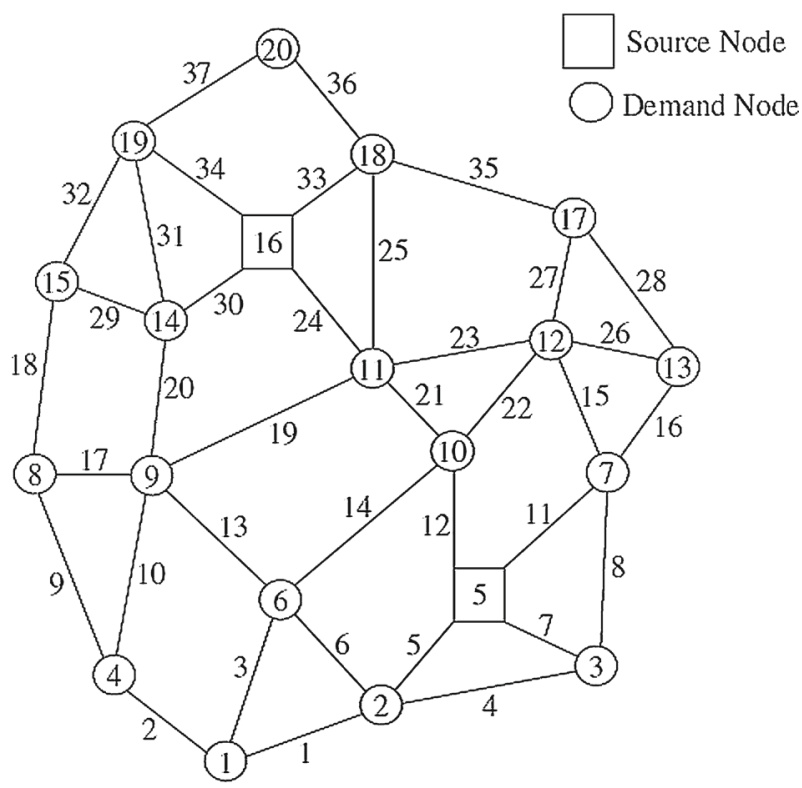

(b) Network 2

Fig. 1 Topologies of Networks 1 and 2 with all the candidate pipes 
Table 1 Results and convergence statistics for 30 optimization runs

\begin{tabular}{|c|c|c|c|c|c|}
\hline Properties & Minimum & Mean & Median & Maximum & Standard deviation \\
\hline GME entropy & 3.380570 & 3.560733 & 3.561684 & 3.592494 & 0.041524 \\
\hline SME entropy & 2.401622 & 2.489328 & 2.476941 & 2.660135 & 0.059723 \\
\hline GME cost $\left(£ 10^{6}\right)$ & 2.177413 & 2.787246 & 2.730261 & 3.552885 & 0.349057 \\
\hline SME cost $\left(£ 10^{6}\right)$ & 1.181715 & 1.293399 & 1.292801 & 1.496615 & 0.074389 \\
\hline $\begin{array}{l}\text { Number of fully looped feasible solutions } \\
\text { (out of 100) }\end{array}$ & 36 & 48.533 & 50 & 57 & 5.778 \\
\hline $\begin{array}{l}\text { Number of partially looped and branched } \\
\text { feasible solutions per } 100\end{array}$ & 0 & 6.2 & 5 & 13 & 3.219 \\
\hline $\begin{array}{l}\text { Smallest surplus residual head for feasible } \\
\text { solutions }(\mathrm{m})\end{array}$ & 0.007 & 0.629 & 0.464 & 2.691 & 0.654 \\
\hline Function evaluations (FEs) for convergence & 314,700 & 733,413 & 806,050 & 979,200 & 208,529 \\
\hline Extinction of all fictitious pipes (FEs) & 1,500 & 4,600 & 3,850 & 17,300 & 3,725 \\
\hline Extinction of $750 \mathrm{~mm}$ pipes (FEs) & 500 & 2,050 & 1,650 & 8,500 & 1,594 \\
\hline Extinction of $700 \mathrm{~mm}$ pipes (FEs) & 900 & 2,583 & 1,950 & 5,700 & 1,406 \\
\hline Extinction of $650 \mathrm{~mm}$ pipes (FEs) & 900 & 4,003 & 2,600 & 17,300 & 3,885 \\
\hline Hypervolume & 0.653 & 0.661 & 0.660 & 0.682 & 0.004 \\
\hline CPU time for convergence (minutes) & 27.35 & 63.75 & 70.06 & 85.11 & 18.13 \\
\hline \multicolumn{6}{|l|}{ (b) Network 2} \\
\hline Properties & Minimum & Mean & Median & Maximum & Standard deviation \\
\hline GME entropy & 4.476402 & 4.872415 & 4.895875 & 5.190007 & 0.185378 \\
\hline SME entropy & 2.981072 & 3.140691 & 3.136344 & 3.306349 & 0.089291 \\
\hline GME cost (millions of CU) & 5.626414 & 6.814409 & 6.843641 & 7.738914 & 0.561343 \\
\hline SME cost (millions of CU) & 2.253554 & 2.549198 & 2.502468 & 2.925169 & 0.179179 \\
\hline $\begin{array}{l}\text { Number of fully looped feasible solutions } \\
\text { (out of 100) }\end{array}$ & 37 & 46.207 & 46 & 52 & 2.631 \\
\hline $\begin{array}{l}\text { Number of partially looped and branched } \\
\text { feasible solutions per } 100\end{array}$ & 2 & 8.586 & 9 & 14 & 3.275 \\
\hline $\begin{array}{l}\text { Smallest surplus residual head for feasible } \\
\text { solutions }(\mathrm{m})\end{array}$ & 0.002 & 0.082 & 0.058 & 0.335 & 0.083 \\
\hline Function evaluations (FEs) for convergence & 552,000 & 905,224 & 949,800 & 997,500 & 106,861 \\
\hline Extinction of all fictitious pipes (FEs) & 13,400 & 39,314 & 41,100 & 80,600 & 14,452 \\
\hline Extinction of $800 \mathrm{~mm}$ pipes (FEs) & 5,400 & 25,914 & 24,600 & 78,200 & 16,222 \\
\hline Extinction of $750 \mathrm{~mm}$ pipes (FEs) & 11,800 & 39,028 & 41,100 & 80,600 & 14,800 \\
\hline Hypervolume & 0.642 & 0.645 & 0.645 & 0.648 & 0.002 \\
\hline CPU time for convergence (minutes) & 69.10 & 113.32 & 118.90 & 124.87 & 13.38 \\
\hline
\end{tabular}

desktop personal computer (Processor: Intel Core 2 Duo, CPU: $2.99 \mathrm{GHz}, \mathrm{RAM}$ : $3.21 \mathrm{~GB}$ ). The population size, cross-over probability and stopping criterion were: $100,1.0$ and $10^{6}$ hydraulic simulations, respectively. The 100 solutions in each of the 30 nondominated sets achieved were then merged. Out of the $30 \times 100$ i.e. 3,000 solutions the final set of 100 nondominated solutions was obtained by a screening procedure that considers the Paretooptimality and diversity (i.e. crowding distance) of the solutions in the objective space (as in NSGA II). The convergence point in the optimization was taken as the point after which there 


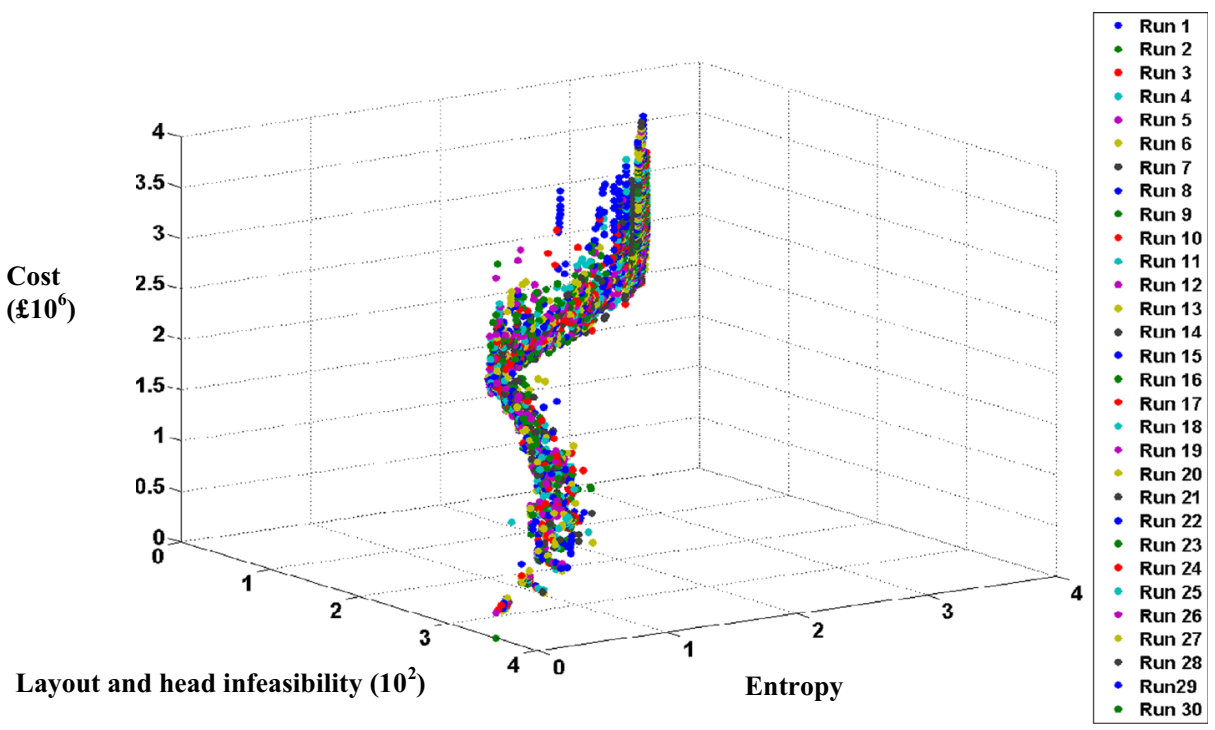

Fig. 2 Pareto-optimal fronts for Network 1 showing 30 optimization runs

was no further improvement in both the entropy and cost for the feasible solution with the highest entropy value.

Given a set of nondominated solutions, the hypervolume is a measure of the fraction of the objective space dominated by the said solutions. Its value increases as the achieved solutions approach the real Pareto-optimal front. The value increases also as the range of solutions in the nondominated set increases or their distribution becomes more uniform. Larger hypervolume values are thus preferred (Knowles 2005). The hypervolume was calculated after normalizing the objectives according to Eq. 8, for each optimization run and the union of all the 30 runs.

\subsection{Sample Network 1}

The network shown in Fig. 1a (Awumah et al. 1990) has one supply node, 17 pipes and 11 demand nodes. The elevation of the nodes is $0 \mathrm{~m}$. The head at the supply node is $100 \mathrm{~m} . H_{i}^{\text {req }}=$ $30 \mathrm{~m}$ for all demand nodes. All pipes have length of $1,000 \mathrm{~m} . R_{i}^{\text {req }}=2$ specifies a fully looped topology. We used 12 pipe diameters $(100,125,150,200,250,300,350,400,450,500,550$ and $600 \mathrm{~mm})$ i.e. $13^{17}=8.65 \times 10^{18}$ solutions including pipe omission. Given $10^{6}$ hydraulic simulations the sampling ratio was $10^{6} / 8.65 \times 10^{18}=8.65 \times 10^{-12}$. Each solution was represented by a 68 -bit chromosome based on a 4-bit pipe-size representation scheme. A 4-bit binary string produces $2^{4}=16$ codes three of which are redundant as there are 13 pipe-size alternatives. We allocated three assumed pipe diameters of 650,700 and $750 \mathrm{~mm}$ to the three redundant codes. The pipe costs were taken as $800 D^{1.5}(£ / \mathrm{m})$ where $D$ is the pipe diameter (in metres). The absolute probability of bit mutation was $1 / 68 \approx 0.015$.

Table 1 shows the general characteristics of the optimization algorithm. The minimum cost achieved for the global maximum entropy (GME) solution was $£ 2,177,413$. The maximum value of entropy for the GME solution was 3.592494. The mean number of function evaluations and CPU time required to achieve convergence were 733,413 and about $64 \mathrm{~min}$, respectively. There is a multiplicity of maximum entropy values and one of the aims of the optimization is to 
a
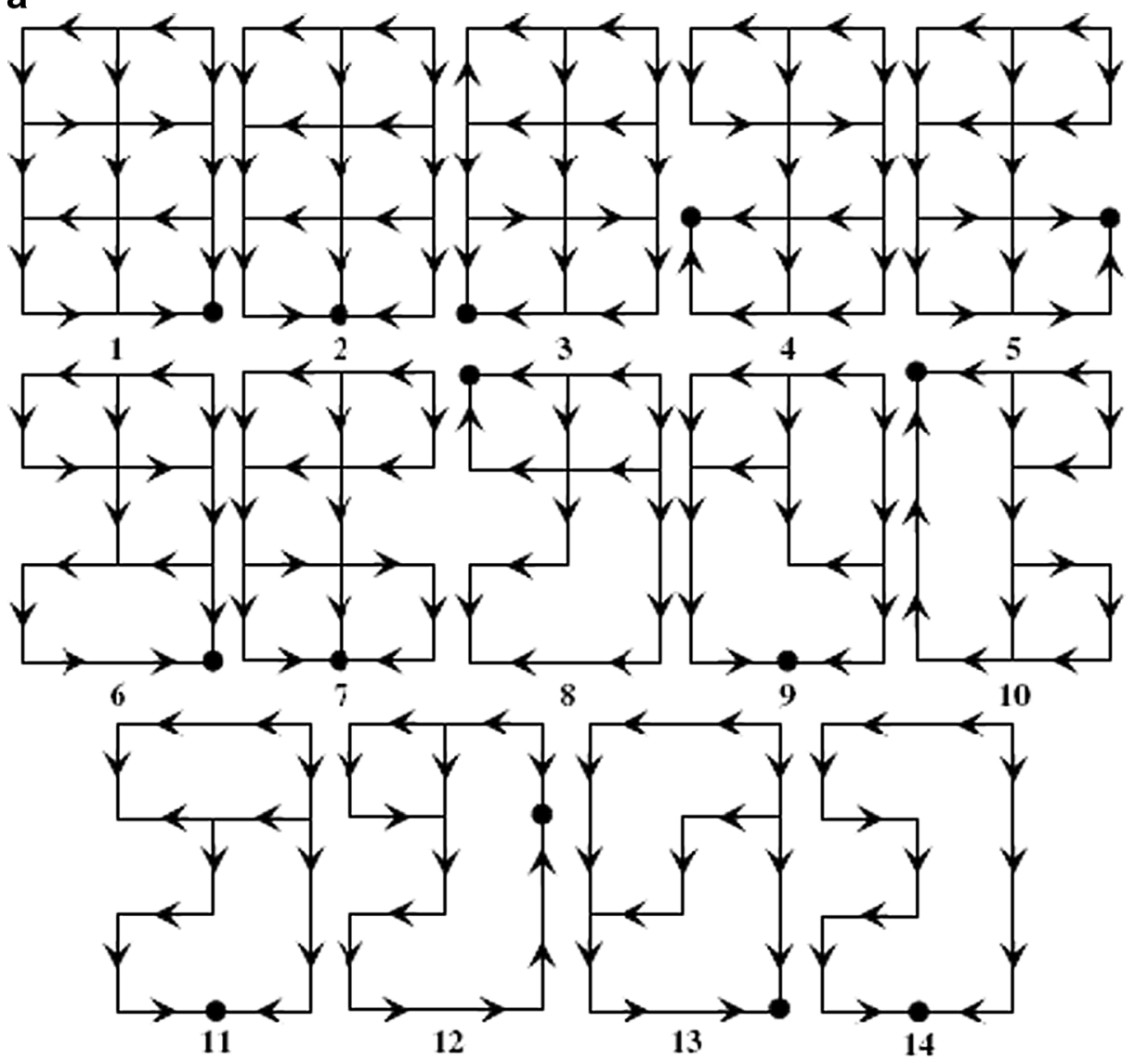

b

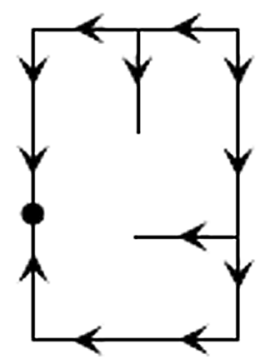

15

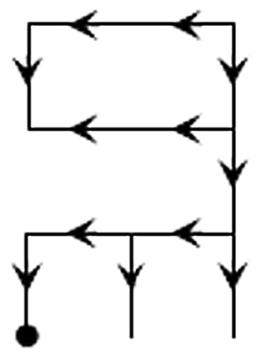

16

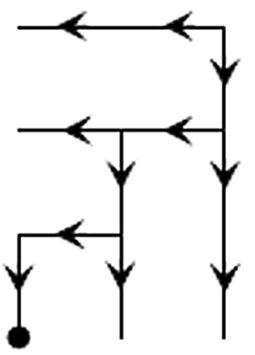

17

Fig. 3 a Topologies and flow directions of fully looped hydraulically feasible maximum entropy families for Network 1. The solid circles represent nodes with the smallest residual heads. b Topologies and flow directions of branched and partially looped hydraulically feasible maximum entropy families for Network 1 . The solid circles represent nodes with the smallest residual heads. c Topologies of looped and partially looped feasible solutions for Network 2. The rectangles represent sources. d Topologies of branched and partially branched feasible solutions for Network 2. The rectangles represent sources

provide a wide range of maximum entropy solutions. The maximum entropy value that is the smallest gives rise to the smallest Maximum Entropy (SME) solution. The minimum cost of the 


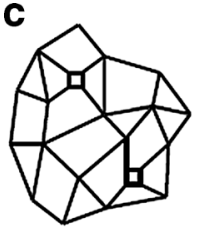

1

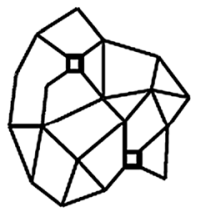

6

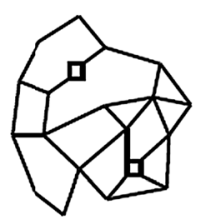

11

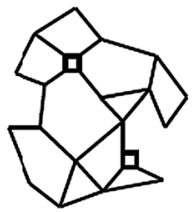

16

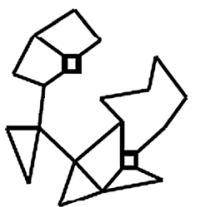

21

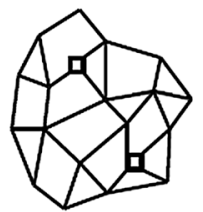

2

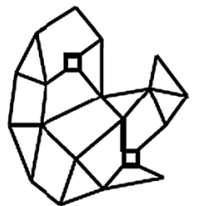

7

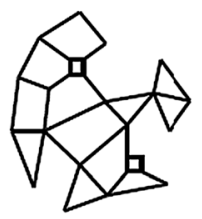

12

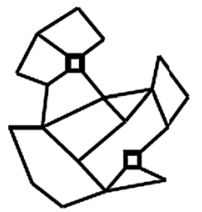

17

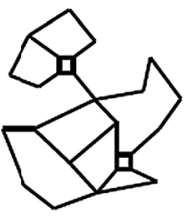

22

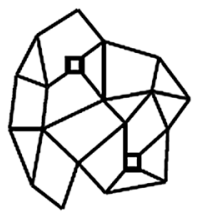

3

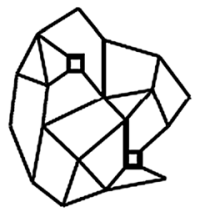

8

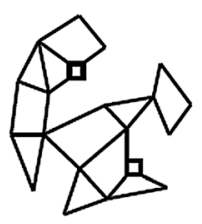

13

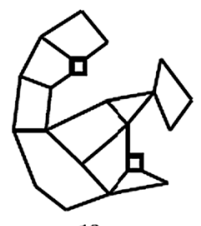

18

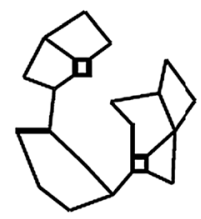

23

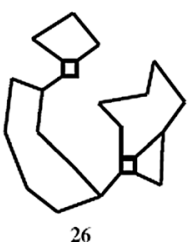

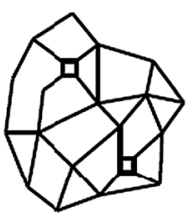

4

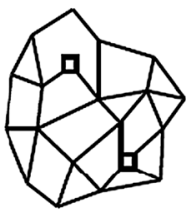

5

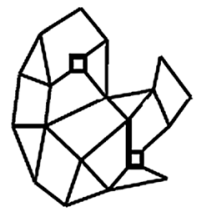

9

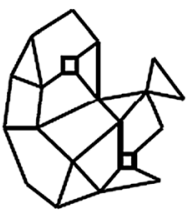

10

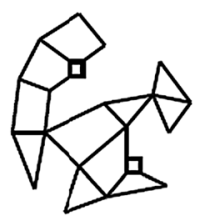

14

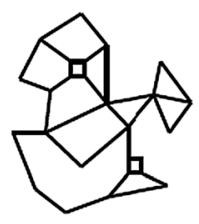

15

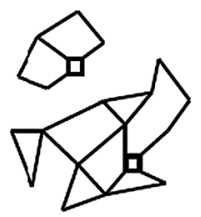

19

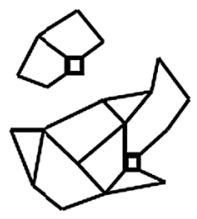

20

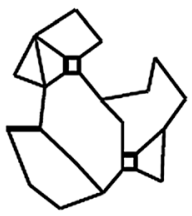

24

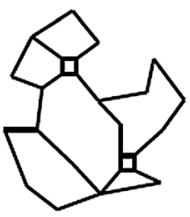

25

Fig. 3 (continued)

SME solution was $£ 1,181,715$. The maximum value of entropy for the SME solution was 2.660135. The minimum surplus head at the critical node was $0.007 \mathrm{~m}$. The optimization model includes multiple conflicting objectives. Therefore, it is not guaranteed that any minimum node pressure constraints will be active. Furthermore, the slack for a limiting minimum node pressure constraint need not be exactly zero, due to the discrete pipe diameters. 


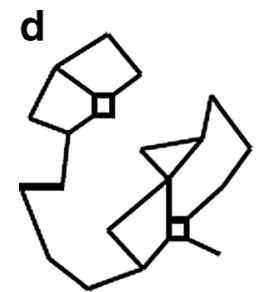

27

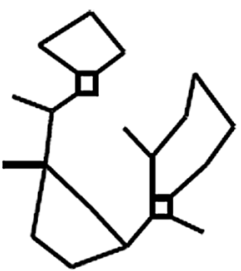

28

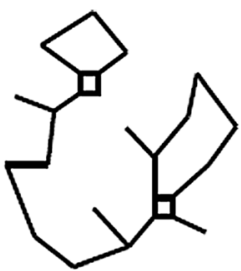

29

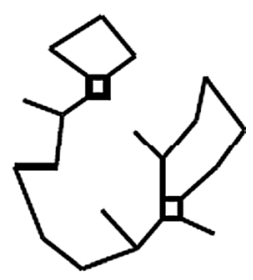

30

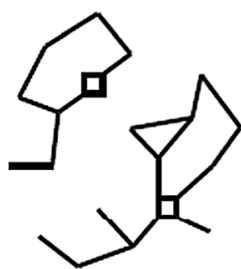

31

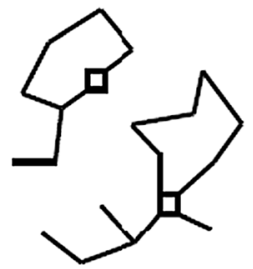

32

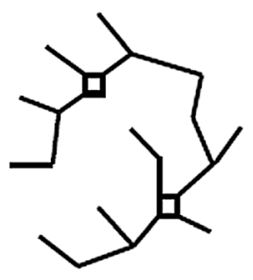

33

Fig. 3 (continued)

Figure 2 shows the frontier-optimal solutions achieved of which the most infeasible solution has cost $=0$; entropy $=0$; topological infeasibility $=24$ (i.e. 2 independent paths per node $\times 12$ nodes); and residual head infeasibility $=330 \mathrm{~m}$ (i.e. 11 demand nodes $\times 30 \mathrm{~m}$ of residual head for each demand node). This solution survives until the end of the optimization because the algorithm is bias-free with respect to constraint violations. Any crossover between this solution and another solution will likely create new layouts. Also, the hypervolume value for the final merged Pareto-optimal front was 0.676. This is similar to the values in Table 1 for the individual optimization runs.

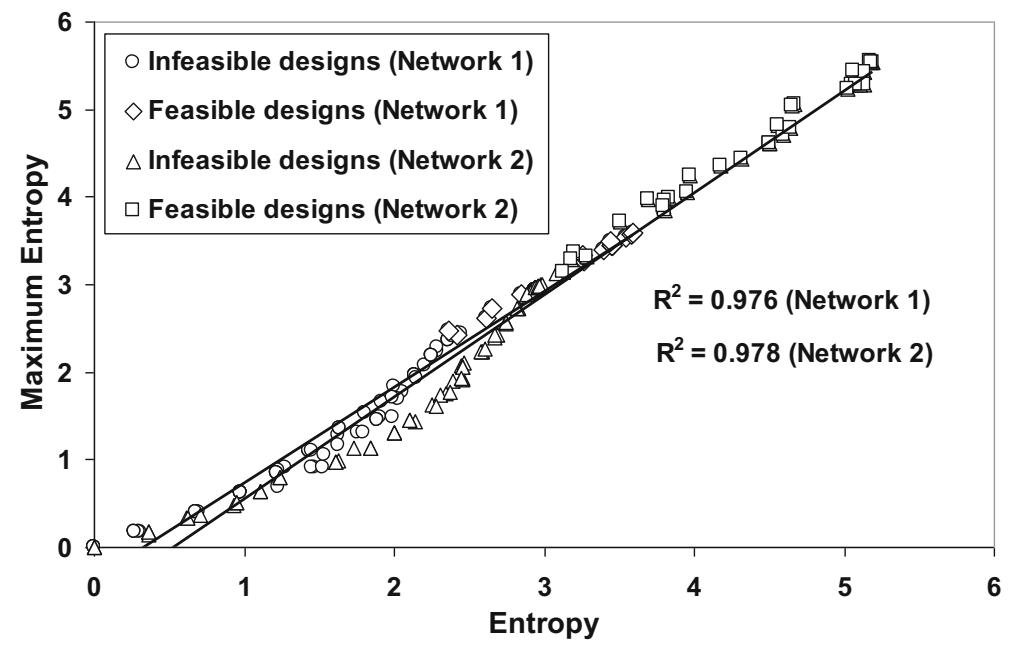

Fig. 4 Achieved vs theoretical maximum entropy values of Networks 1 and 2 
Tables 2 and 3 (in the appendix) illustrate the range of feasible solutions achieved. The final Pareto-optimal set has 23 hydraulically feasible fully-looped solutions and 11 different fully looped topologies (see Fig. 3a). All infeasible solutions in the final Pareto-optimal set were found to be topologically infeasible (i.e. $\exists i: R_{i}<R_{i}^{\text {req }}=2$ ), of which only three were hydraulically feasible (i.e. $H_{i} \geq H_{i}^{r e q}=30 \mathrm{~m} ; \forall i$ ) (see Fig. $3 \mathrm{~b}$ ). Fig. 4 provides further confirmation that the solutions achieved are essentially maximum entropy solutions.

Figure 5 shows the progress of the optimization. The fictitious pipe diameters were eliminated in the early stages consistently (Fig. 5b-c). Prior to their complete elimination, fictitious pipe diameters were present in both hydraulically feasible and infeasible solutions. Also, the observed rates of elimination reflected the pipe sizes and costs (Table 1 and Fig. 5c). On average the larger more expensive assumed diameters were eliminated more quickly. These results suggest convergence of the algorithm is very quick and the proposed procedure for handling redundant binary strings is highly effective.

\subsection{Sample Network 2}

The network shown in Fig. $1 \mathrm{~b}$ has two supply nodes, 18 demand nodes and 37 pipes. The node demands, required residual heads, pipe lengths and costs are available in Morgan and Goulter (1985). There are 13 pipe sizes, i.e. $14^{37}=2.55 \times 10^{42}$ solutions including pipe omission. Given $10^{6}$ hydraulic simulations the sampling ratio was $10^{6} / 2.55 \times 10^{42}=3.92 \times$ $10^{-37}$. A 4-bit binary substring for each pipe size gave a chromosome with length of 148 bits. The absolute probability of bit mutation was $1 / 148$. With 14 options for each pipe, two

a

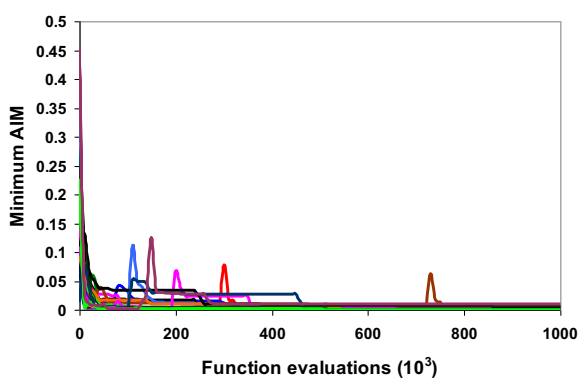

b

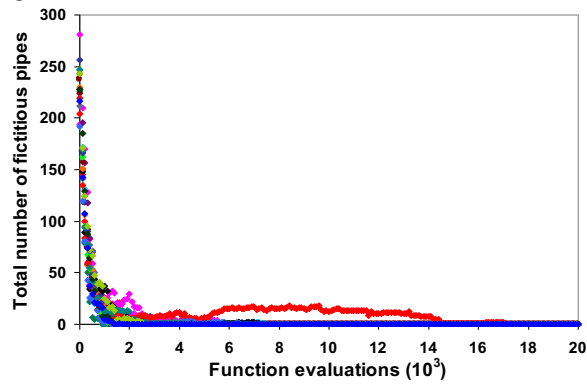

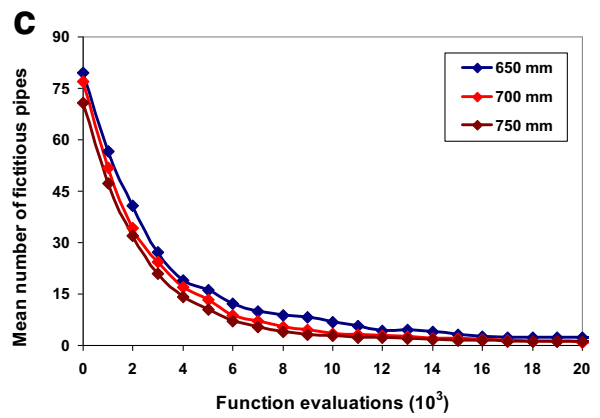

d

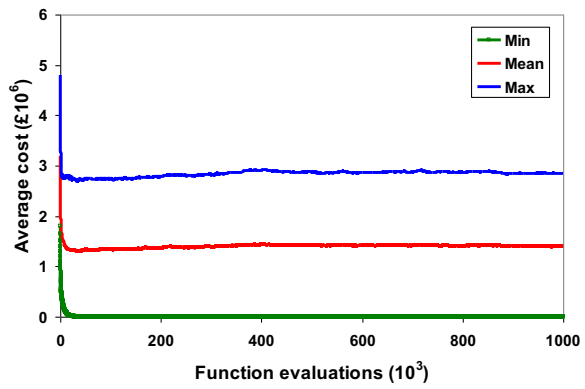

Fig. 5 Illustration of convergence characteristics with Network 1. (a) and (b) show 30 individual optimization runs while (c) and (d) show averages based on the 30 optimization runs. AIM abbreviates the entropy-augmented infeasibility measure 
Fig. 6 Pareto-optimal fronts for Network 2 based on the union of the results of 30 optimization runs

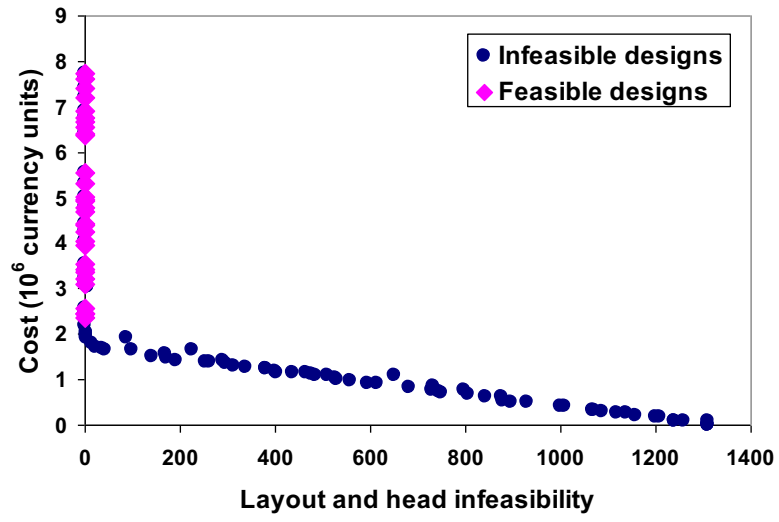

(a) Infeasibility vs. cost

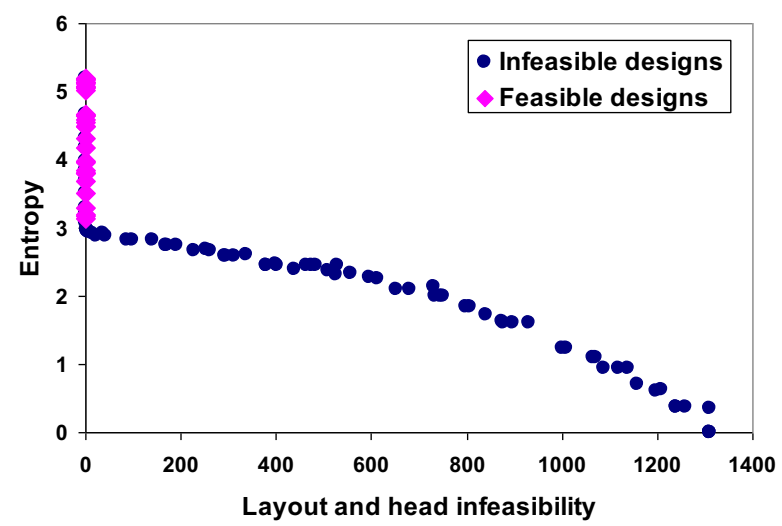

(b) Infeasibility vs. entropy

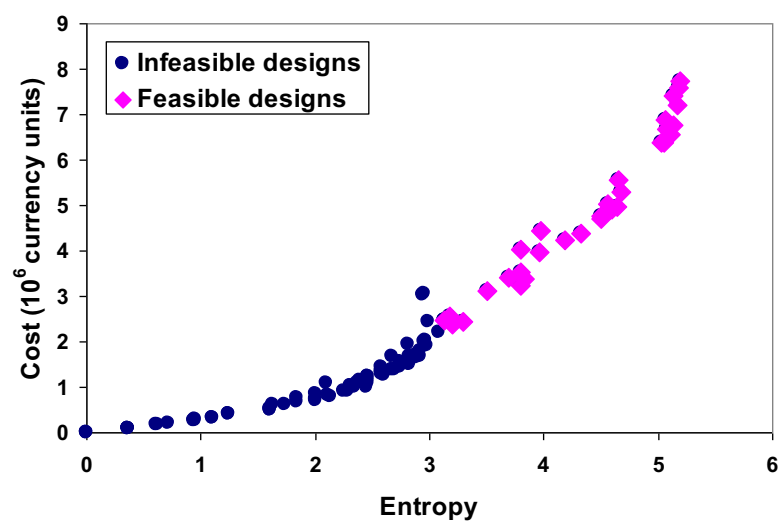

(c) Entropy vs. cost 
codes (out of $2^{4}=16$ ) were redundant. Two fictitious pipe diameters of $750 \mathrm{~mm}$ and $800 \mathrm{~mm}$, with costs of $520.9 / \mathrm{m}$ and $591.7 / \mathrm{m}$ respectively, were allocated to the two redundant codes by extending the cost function of the real pipe diameters. The costs are in generic currency units (CU).

Table 1 summarizes the results achieved. The final Pareto-optimal front had 31 feasible solutions based on 26 layouts (Fig. 3c) that are fully non-dendritic (i.e. layouts with no dead ends). Additionally, seven branched and partially-branched feasible solutions were achieved (Fig. 3d). The cheapest fully-looped feasible solution (Layout 24 in Fig. 3c) with a cost of 2,374,070 CU (Solution 29 in Table 4) had 12 pipes removed. The most expensive fullylooped feasible solution (Layout 2 in Fig. 3c) with a cost of 7,738,914 CU (Solution 4 in Table 4) had one pipe removed. Figure 6 shows the relationship between the cost, entropy and infeasibility.

\section{Conclusions}

A new approach to the simultaneous topology and reliability-based pipe-size optimization of water distribution systems has been developed. The method provides a multiplicity of costeffective candidate solutions distributed among a diverse range of optimal topologies. We used statistical entropy as a computationally efficient surrogate measure of the hydraulic reliability/ redundancy and reduced the computational complexity by introducing a new entropy-augmented infeasibility measure. Our optimization model includes the following essential features: (a) entropy maximization within individual feasible sets of flow directions; (b) entropy maximization across all feasible sets of flow directions within individual topologies; (c) entropy maximization across all topologies; (d) minimization of initial construction cost; (e) promotion of a wide variety of alternative solutions; (f) satisfaction of minimum topological adequacy (i.e. supply node and demand node reachability); (g) satisfaction of minimum topological redundancy (i.e. alternative independent supply paths); and (h) adequacy of nodal flows and pressures.

Clearly, many complex objectives and constraints are involved. The entropy-augmented infeasibility measure introduced here simplifies the optimization and reduces the computational complexity considerably as the objectives have been reduced to only three (Saxena et al. 2013; Deb et al. 2002). The optimization problem addressed has six objectives. Sinha et al. (2013) emphasize that the computational solution of a six-objective optimization problem is a 'formidable task' for most evolutionary multi-objective optimization algorithms that aim to generate the entire Pareto-optimal front. Some of the challenges include: difficulties in achieving at once both diversity of solutions and convergence on the true Pareto-optimal front; and difficulties arising from the inability to visualize the Paretooptimal front geometrically.

The genetic algorithm approach proposed allows full exploitation of all the efficient feasible and infeasible solutions generated in the optimization. Any redundant binary codes created are eliminated in a seamless and generic way through natural selection. This avoids arbitrary loss of potentially useful genetic material and preserves the quality of the information that is transmitted from one generation to the next. The results for the two test problems considered are sufficiently encouraging to suggest further research to improve and extend the algorithms proposed may be beneficial.

Aknowledgments The first author's PhD programme was funded by the Government of Libya. This research was funded in part by the UK Engineering and Physical Sciences Research Council (EPSRC Grant Reference EP/G055564/1). 


\section{Appendix}

Table 2 Nondominated feasible solutions achieved for Network 1

(a) Fully looped feasible solutions

\begin{tabular}{|c|c|c|c|c|c|c|c|c|}
\hline $\begin{array}{l}\text { Solution } \\
\text { number }\end{array}$ & Cost $\left(£ 10^{6}\right)$ & $\begin{array}{l}{ }^{\text {a }} \text { Surplus } \\
\text { head (m) }\end{array}$ & $\begin{array}{c}{ }^{\mathrm{b}} \text { Critical } \\
\text { node }\end{array}$ & $\begin{array}{l}\text { Achieved } \\
\text { entropy } \\
(S)\end{array}$ & $\begin{array}{c}\text { Maximum } \\
\text { entropy } \\
(\mathrm{ME})\end{array}$ & $M E-S$ & $G M E-M E$ & $\begin{array}{l}{ }^{\mathrm{d}} \mathrm{ME} \\
\text { family }\end{array}$ \\
\hline 1 & 2.52235 & 19.734 & 9 & 3.592494 & $3.592800^{\mathrm{c}}$ & 0.000306 & 0.000000 & 1 \\
\hline 2 & 1.592572 & 9.817 & 10 & 3.257305 & 3.330590 & 0.073285 & 0.262210 & 2 \\
\hline 3 & 1.823409 & 2.083 & 11 & 3.439667 & 3.489588 & 0.049921 & 0.103213 & 3 \\
\hline 4 & 2.756591 & 21.594 & 8 & 3.581014 & 3.581115 & 0.000101 & 0.011685 & 4 \\
\hline 5 & 1.977641 & 11.642 & 6 & 3.545526 & 3.546760 & 0.001234 & 0.046041 & 5 \\
\hline 6 & 3.138684 & 38.903 & 9 & 3.449581 & 3.449665 & 0.000084 & 0.143135 & 6 \\
\hline 7 & 3.067751 & 38.729 & 9 & 3.449580 & 3.449665 & 0.000085 & 0.143135 & 6 \\
\hline 8 & 2.930185 & 36.096 & 9 & 3.449268 & 3.449665 & 0.000397 & 0.143135 & 6 \\
\hline 9 & 2.235305 & 8.626 & 9 & 3.448149 & 3.449665 & 0.001517 & 0.143135 & 6 \\
\hline 10 & 1.871266 & 5.864 & 10 & 3.395190 & 3.398060 & 0.002870 & 0.194740 & 7 \\
\hline 11 & 1.292923 & 1.350 & 2 & 2.850790 & 2.891747 & 0.040958 & 0.701053 & 8 \\
\hline 12 & 1.271386 & 3.443 & 10 & 2.647933 & 2.723657 & 0.075724 & 0.869144 & 9 \\
\hline 13 & 2.969728 & 33.350 & 2 & 3.265855 & 3.269803 & 0.003947 & 0.322998 & 10 \\
\hline 14 & 1.173127 & 1.910 & 10 & 2.367236 & 2.469176 & 0.101940 & 1.123624 & 11 \\
\hline 15 & 2.849506 & 35.237 & 3 & 2.940251 & 2.940255 & 0.000004 & 0.652545 & 12 \\
\hline 16 & 2.839981 & 34.462 & 3 & 2.940250 & 2.940255 & 0.000005 & 0.652545 & 12 \\
\hline 17 & 2.769049 & 34.041 & 3 & 2.940247 & 2.940255 & 0.000008 & 0.652545 & 12 \\
\hline 18 & 2.729939 & 32.628 & 3 & 2.940223 & 2.940255 & 0.000033 & 0.652545 & 12 \\
\hline 19 & 2.683465 & 32.394 & 3 & 2.940159 & 2.940255 & 0.000097 & 0.652545 & 12 \\
\hline 20 & 2.605798 & 30.773 & 3 & 2.940102 & 2.940255 & 0.000154 & 0.652545 & 12 \\
\hline 21 & 2.535235 & 23.781 & 3 & 2.939597 & 2.940255 & 0.000659 & 0.652545 & 12 \\
\hline 22 & 1.529674 & 9.394 & 9 & 2.614232 & 2.624432 & 0.010200 & 0.968369 & 13 \\
\hline 23 & 1.721305 & 6.330 & 10 & 2.419348 & 2.425825 & 0.006477 & 1.166975 & 14 \\
\hline \multicolumn{9}{|c|}{ (b) Branched or partially looped feasible solutions } \\
\hline $\begin{array}{l}\text { Solution } \\
\text { number }\end{array}$ & Cost $\left(£ 10^{6}\right)$ & $\begin{array}{l}\text { Surplus } \\
\text { head (m) }\end{array}$ & $\begin{array}{r}\text { Critical } \\
\text { node }\end{array}$ & $\begin{array}{l}\text { Achieved } \\
\quad \text { entropy }(S)\end{array}$ & $\begin{array}{c}\text { Maximum } \\
\text { entropy } \\
\text { (ME) }\end{array}$ & $M E-S$ & $G M E-M E$ & $\begin{array}{l}\text { ME } \\
\text { family }\end{array}$ \\
\hline 24 & 1.508359 & 18.840 & 8 & 2.447343 & 2.447345 & 0.000002 & 1.145456 & 15 \\
\hline 25 & 1.075510 & 0.842 & 11 & 2.387568 & 2.404150 & 0.016582 & 1.188651 & 16 \\
\hline 26 & 1.050212 & 0.503 & 11 & 2.360799 & 2.360799 & 0.000000 & 1.232002 & 17 \\
\hline
\end{tabular}

\footnotetext{
${ }^{a}$ Refers to the excess residual head at the node with the smallest residual head

${ }^{\mathrm{b}}$ Refers to the node with the smallest residual head

${ }^{c}$ The global (i.e. greatest) maximum entropy (GME) value found

${ }^{d}$ The maximum entropy family here refers to any subset of solutions whose topology and pipe flow directions are identical
} 


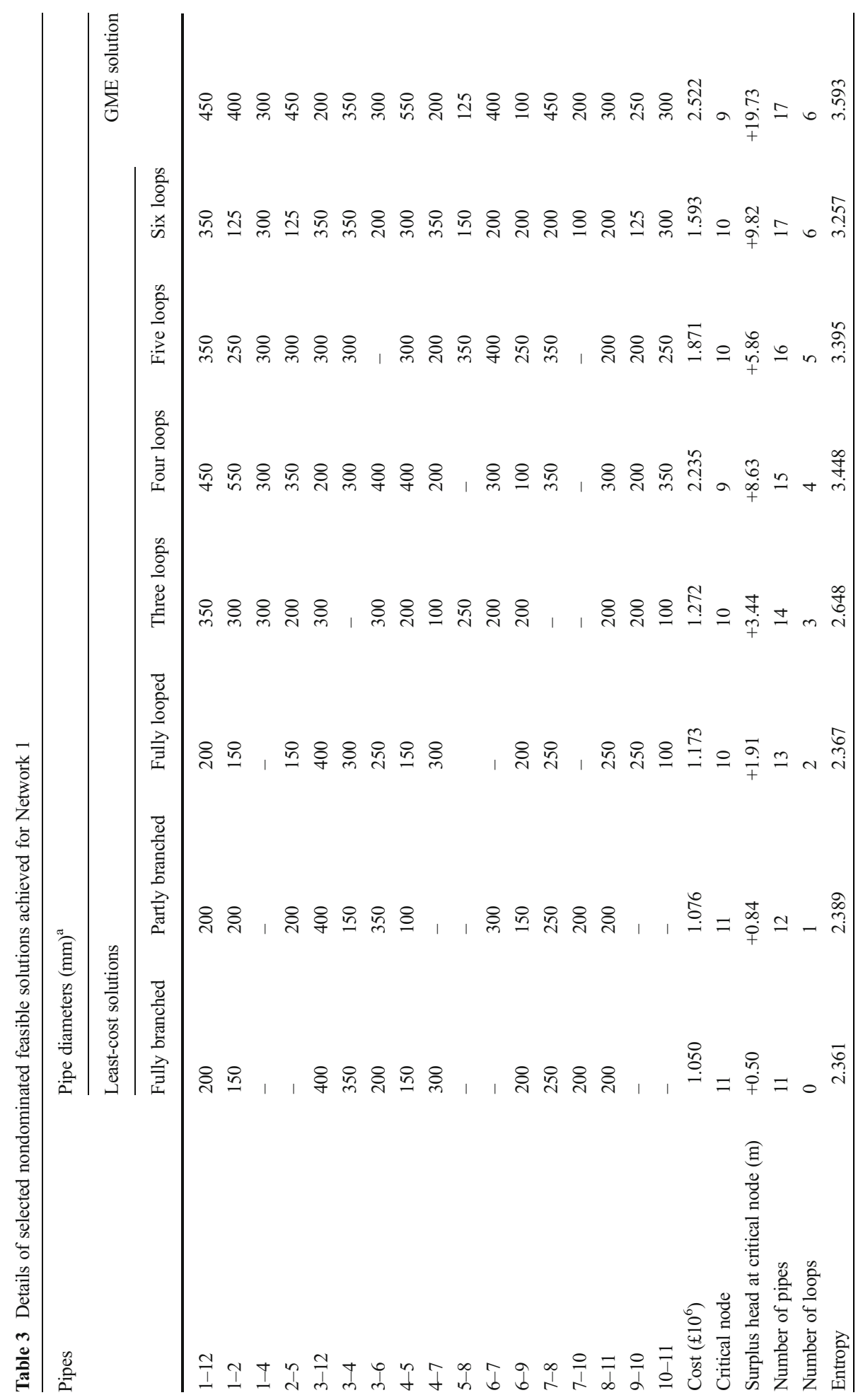




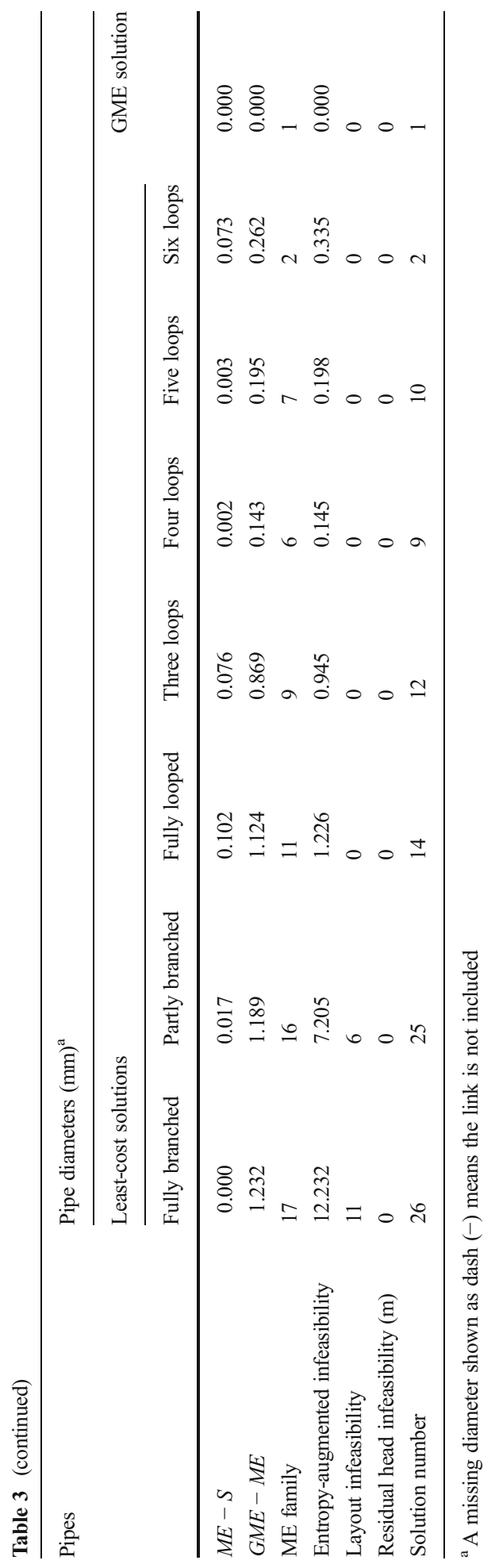


总

।

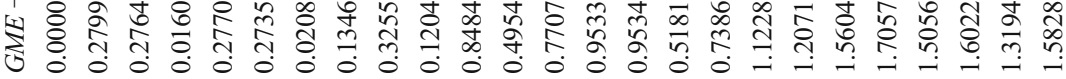

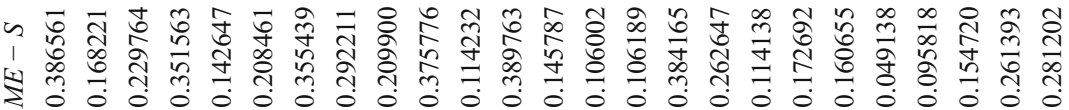

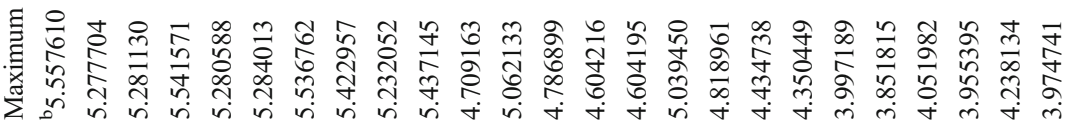
5) 产

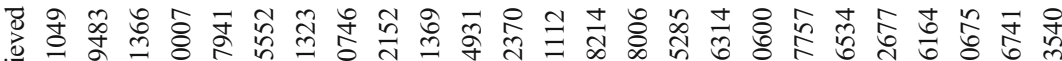

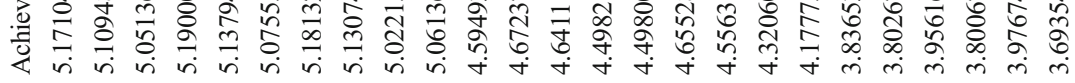
$\frac{8}{8}$

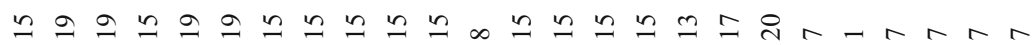
ఏ 节 营 号

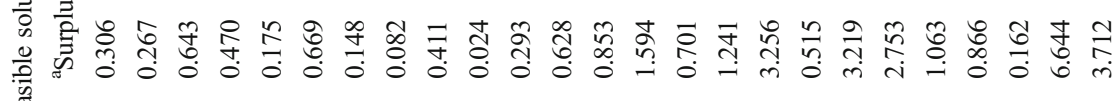
चี ठ ठें ती ॠ 3 तु 


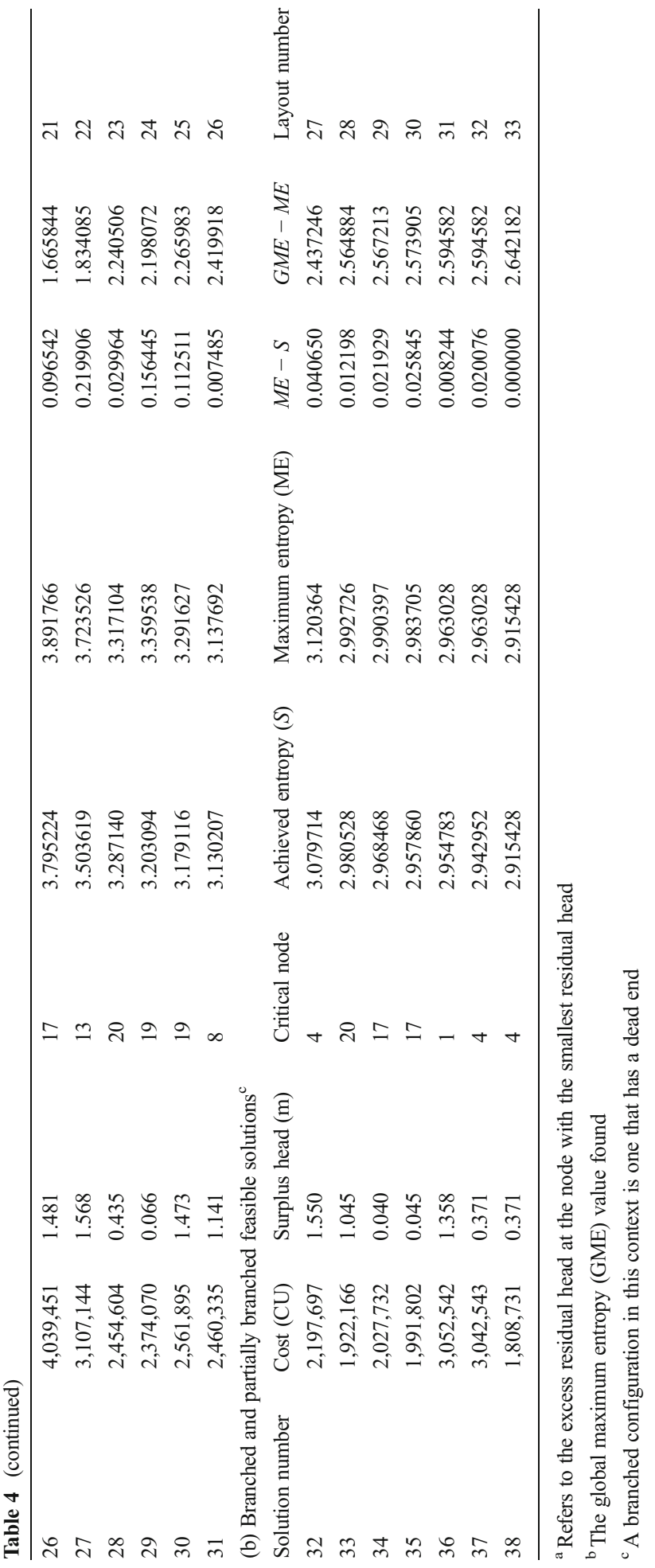


Open Access This article is distributed under the terms of the Creative Commons Attribution License which permits any use, distribution, and reproduction in any medium, provided the original author(s) and the source are credited.

\section{References}

Afshar MH, Jabbari I (2007) Simultaneous layout and size optimization of pipe networks using genetic algorithms. Arab J Sc Eng 33(2B):391-409

Ang WK, Jowitt PW (2005) Path entropy method for multiple-source water distribution networks. Eng Optim 37(7):705-715

Awumah K, Goulter I (1992) Maximizing entropy-defined reliability of water distribution networks Eng. Optimization 20(1):57-80

Awumah K, Bhatt SK, Goulter IC (1989) An integer programming model for layout design of water distribution networks. Eng Optim 15(1):57-70

Awumah K, Goulter I, Bhatt SK (1991) Entropy-based redundancy measures in water distribution network design. J Hydraul Eng 117(5):595-614

Baños R, Reca J, Martínez J, Gil C, Márquez A (2011) Resilience indexes for water distribution network design: a performance analysis under demand uncertainty. Water Resour Manag 25(10):2351-2366

Cembrowicz RG (1992) Water supply systems optimization for developing countries. In: Coulbeck B, Evans E (eds) Pipeline systems. Kluwer, London, pp 59-76

Davidson JW, Goulter IC (1995) Evolution program for design of rectilinear branched networks. J Comput Civ Eng 9(2):112-121

Deb K, Pratap A, Agarwal S, Meyarivan T (2002) A fast and elitist multiobjective genetic algorithm: NSGA-II. IEEE Trans Evol Comput 6(2):182-197

Dridi L, Parizeau M, Maihot A, Villeneuve J-P (2008) Using evolutionary optimization techniques for scheduling water pipe renewal considering a short planning horizon. Comput-Aided Civ Infrastruct Eng 23(8):625-635

Geem ZW, Kim JH, Yoon YN (2000) Optimal layout of pipe networks using harmony search. Proceedings of 4th International Conf. on Hydro-Science and Engineering Seoul, South Korea

Herrera F, Lozano M, Verdegay JL (1998) Tackling real-coded genetic algorithms: operators and tools for behavioural analysis. Artif Intell Rev 12:265-319

Jayaram N, Srinivasan K (2008) Performance-based optimal design and rehabilitation of water distribution networks using life cycle costing. Water Resour Res 44(1)

Kessler A, Ormsbee L, Shamir U (1990) A methodology for least-cost design of invulnerable water distribution networks. Civ Eng Syst 7(1):20-28.

Knowles J (2005) A hybrid algorithm with on-line landscape approximation for expensive multiobjective optimization problems. IEEE Trans Evol Comput 10(1):50-66

Kougias IP, Theodossiou NP (2013) Multi-objective pump scheduling optimization using harmony search algorithm and polyphonic HSA. Water Resour Manag 27(5):1249-1261

Morgan DR, Goulter IC (1982) Least cost layout and design of looped water distribution systems. Proceedings of 9th International Symposium on Urban Hydrology, Hydraulics and Sediment control, Lexington, KY, USA, $27-30$

Morgan DR, Goulter IC (1985) Optimal urban water distribution design. Water Resour Res 21(5):642-652

OFWAT (2008) Guaranteed Standards Scheme [Website accessed 26 February 2013] http://www.ofwat.gov.uk/ consumerissues/rightsresponsibilities/waterpressure.

Prasad TD, Park NS (2004) Multi-objective genetic algorithms for design of water distribution networks. J Water Resour Plan Manag 130(1):73-82

Press WH, Teukolski SA, Vetterling WT, Flannery BP (2003) Numerical Recipes in FORTRAN 77, Vol. 1, Cambridge University Press, p. 346-7

Raad DN, Sinske AN, van Vuuren JH (2010) Comparison of four reliability surrogate measures for water distribution systems design. Water Resour Res 46(5):W05524

Ray T, Tai K, Seow C (2001) An evolutionary algorithm for multiobjective optimization. Eng Optim 33(3):399-424

Reca J, Martinez J, Banos R, Gil C (2008) Optimal design of gravity-fed looped water distribution networks considering the resilience index. J Water Resour Plan Manag 134(3):234-238

Rossman LA (2000) EPANET 2 users manual. Water supply and water resources division, national risk management research laboratory. U.S. EPA, Cincinnati

Rowel WF, Barnes JW (1982) Obtaining the layout of water distribution systems. J Hydraul Div ASCE 108(1): $137-148$ 
Saleh HAS, Tanyimboh TT (2013) Coupled topology and pipe size optimization of water distribution systems. Water Resour Manag. doi:10.1007/s11269-013-0439-4

Saleh S, Barlow E, Tanyimboh TT (2012) Unbiased and accurate assessment of surrogate measures of hydraulic reliability of water distribution systems. 14th Water Distribution Systems Analysis Conference, Adelaide, Australia, ISBN 978-1-922197-58-9, 148-157

Saxena KS, Duro JA, Tiwari A, Deb K (2013) Objective reduction in many-objective optimization: linear and non-linear algorithms. Trans Evol Comput 17(1):77-99

Shannon C (1948) A math. theory of communication. Bell Syst Tech J 27(3):379-428

Siew C, Tanyimboh TT (2012) Penalty-free feasibility boundary convergent multi-objective evolutionary algorithm for the optimization of water distribution systems. Water Resour Manag 26(15):4485-4507

Sinha A, Saxena DK, Deb K, Tiwari A (2013) Using objective reduction and interactive procedure to handle many-objective optimization problems. Appl Soft Comput 13(1):415-427

Swamee PK, Sharma AK (2008) Design of water supply pipe networks. Wiley, New Jersey

Tanyimboh TT, Sheahan C (2002) A maximum entropy based approach to the layout optimization of water distribution systems. Civ EngEnviron Syst 19(3):223-254

Tanyimboh TT, Templeman AB (1993) Calculating maximum entropy flows in networks. J Oper Res Soc 44(4): 383-396

Tanyimboh TT, Tietavainen MT, Saleh S (2011) Reliability assessment of water distribution systems with statistical entropy and other surrogate measures. Water Sci Technol Water Supply 11(4):437-443

Todini E (2000) Looped water distribution networks design using a resilience index based approach. Urban Water 2(2):115-122

Vaabel J, Ainola L, Koppel T (2006) Hydraulic power analysis for determination of characteristics of a water distribution system. Proceedings of 8th Annual Water Distribution Systems Analysis Symposium, Cincinnati, Ohio, USA

Walters GA, Smith DK (1995) Evolutionary design algorithm for optimal layout of tree networks. Eng Optim 24(4):261-281

Yassin-Kassab A, Templeman AB, Tanyimboh TT (1999) Calculating maximum entropy flows in multi-source, multi-demand networks. Eng Optim 31(6):695-729 